\title{
OVERVIEW OF COVID-19 IN RURAL LIVELIHOOD IN PAKISTAN: ITS ORIGIN, TRANSMISSION, SYMPTOMS, TREATMENT
}

aFarhana Nosheen*, bNazia Malik, bAnam Afzal, bWaseem Nawaz

a Department of Home Economics, Government College University, Faisalabad, Pakistan.

${ }^{b}$ Department of Sociology, Government College University, Faisalabad, Pakistan.

\section{ART ICLE INFO}

\section{Article History}

Received: January 03, 2021

Revised: August 11, 2021

Accepted: August 28, 2021

\section{Keywords}

SARS-CoV-2

COVID-19

Transmission

Symptoms

Treatment

Vaccination

Personal hygiene
A B S T R A C T

About 138 million population live in rural areas of Pakistan. Evidence confirmed that COVID-19 cases were found in rural areas of Pakistan distinctively. Vaccination is the best protection against the virus. In this paper, the main determinants, characteristics, safety precautions, and current statistics related to COVID-19 in rural areas of Pakistan are presented. This study focuses on a rural population that is highly susceptible to COVID-19 and has a relatively high fatality rate in recent months due to closer contact with human, pet and animals. Measures to prevent transmission of COVID-19 was very successful for younger and older aged people in Pakistan. The majority of patients with COVID-19 typically initially had a sore throat, cough, pneumonia, diarrhoea and fever. The situation in Pakistan remained in control as compared to the rest of whole world. Additionally, after a long lockdown the second and third wave of COVID-19 also had fewer effects on the Pakistan population compared to many other countries. The best cure of the COVID-19 infection should be vaccinated and also focused on personal care, hygiene, take ample sunlight, fresh air, and ensure personal protection as well as social distancing. Moreover, the Pakistan government should provide guidelines and training to healthcare workers, and safety essentials to be imposed on people who violate standard operating procedure (SOPs) like levied penalties, sealing shops, send to jails etc. Additionally, now that the vaccine has been introduced, adaptations to COVID-19 safety restrictions should be made and include mandatory vaccination as well as precautionary measures for all citizens.

Corresponding Author: Farhana Nosheen

Email: farhananosheen@gcuf.edu.pk

(C) The Author(s) 2021.

\section{INTRODUCTION}

The Coronaviruses are linked to the Coronaviridae family in the order of the Nidovirales (not sure what this means). Corona characterizes crown-like spikes of the virus's external surface, referred to as a coronavirus. Coronaviruses are minute in size (65-125 $\mathrm{nm}$ in diameter) and comprise a single-stranded RNA as a nucleic substantial, in length size ranging from 26-32kbs. Coronaviruses subgroups family are alpha (a), beta (b), gamma (c) and delta (d) coronavirus. The severe acute respiratory syndrome coronavirus (SARS-CoV), H5N1 influenza A, H1N1 2009 and Middle East respiratory syndrome coronavirus (MERS-CoV) with the source of acute lung injury (ALI) and acute respiratory distress syndrome (ARDS) lead to pulmonic letdown and fatality outcome. it was thought that all these viruses only effect animals' infection. Before the COVID-19 outbreak, the severe acute respiratory syndrome initiated by SARS- 
CoV, 2002 in Guangdong, China (Zhong et al., 2020). In late December 2019, Coronavirus was a challengeable pathogen with direct target to the human respiratory system. Preceding coronaviruses outbreaks included the severe acute respiratory syndrome (SARS-CoV) and the Middle East respiratory syndrome (MERS-CoV) that were threats to public health with the unknown etiology. At the end of 2019, with an initial diagnosis pneumonia in patients was considered as SARS and MERS COVs. Epidemiologically mostly patients were connected toward seafood intake by the wet animal in Wuhan at Hubei Province, China (Bogoch et al., 2020; Lu, Zhao, et al., 2020). The World Health Organization (WHO) on 11 February 2020 announced that there was an "epidemic disease" caused by 2019-CoV, "coronavirus disease (COVID-19)" (Wang, Cao, et al., 2020).

COVID-19 was defined as the respiratory disease caused by SARS-CoV-2 that emerged in China in 2019. These viruses had only infected animals until the world observed a severe acute respiratory syndrome outbreak caused by SARS-CoV, 2002 in after a decade later in Middle Eastern countries began by endemic, another pathogenic coronavirus, identified as Middle East respiratory syndrome coronavirus (MERS-CoV) and now COVID 19 (Gorbalenya et al., 2020). Therefore, The International Committee on Taxonomy of Viruses has renamed as SARS-CoV-2 "Severe Acute Respiratory Syndrome Coronavirus-2". (SARS-CoV-2) due to the previously provisionally named 2019-nCoV (Wang, Cao, et al., 2020).

Approximately $65 \%$ population is living in rural areas of Pakistan and distinctively effected by the COVID-19 pandemic. This research paper is not field research and basically it is desk research aiming to review and spread different related aspects of COVID-19 like symptoms, transmission, treatment options and controlling this pandemic among rural livelihoods in order to avoid further spread to save the human, social and economic loss of masses. This paper is entirely based on review of different literature available from different outlets.

Rural areas of Pakistan are less organized in responding to the indirect and direct impacts of the crisis. Out of the 734 million poor people affected by the COVID-19 crisis, $80 \%$ reside in rural areas, and $76 \%$ are involved in agriculture. Additionally, rural communities have less adequate access to health services, education, internet, sanitation, social protection, public infrastructure and communication technology.
The prevalent challenge facing rural communities during COVID-19 is health façade that depends on where they are living, getting infections and availability of health services. Mostly rural livelihood considered more susceptible regarding CDC's Social Vulnerability Index (SVI). The SVI includes reasons as socioeconomic status, housing, housing, language, ethnicity, and race, which can be helpful in shaping, how to support rural areas during, before, and after COVID-19 (https://svi.cdc.gov/).

Pakistan's poultry, meat and food processing industries are largely located in rural areas. Often workers in these industries involve closer physical contact during working than the recommended distance, which increases the risk of these workers getting COVID-19. These workers are not only at risk of being infected with COVID-19, but also are the cause of the rapid spread among communities (ruralhealth@cdc.gov). Rural households are generally in contact with pets, visiting fairs and animal exhibitions which can be spread of Virus from people to certain types of animals and pets.

The Rural Support Programmer (RSP) Network and its partners are working with the local governments and other international donors to undertake numerous activities to raise awareness of how to protect oneself against COVID-19. It may be reducing the spread of the virus in the rural communities. RSPs are actively working on anti-COVID-19 response with communities in 126 districts across Pakistan, in 2,983 union councils through involvement of 69,454 community institutions, with a membership of 1 million people. The response activities are ongoing in all provinces, Gilgit-Baltistan and $\mathrm{AJK}$ in close collaboration with the government authorities who are working closely with community institutions to address the challenge of the COVID-19 pandemic. This collaborative network provides an ideal outreach to rural communities, particularly in remote, rural Pakistan.

RSPs are facilitating links between government and rural communities. RSPs and community activists are present on numerous provincial, district, tehsil and union council committees, in order to assist government in identifying the poorest households eligible for zakat (annual charity given to the poor by wealthier Muslims) cash and food rations etc.

RSPs are encouraging communities to help the neediest households amongst them which is true self help and community philanthropy. We see it in hundreds of 
villages across Pakistan - members of Community Institutions buying rations, using their own saving or collecting funds to feed the poorest in their villages during pandemic.

RSPs are relaying critical messages to communities in villages and in some cities and towns regarding vaccination, social distancing, hand washing with soap, staying home to stay safe during the current national lockdown. Messages in rural areas are spread mainly through community institutions, via phone messages created for this purpose, through community activists and small group meetings between RSP staff and activists, strictly observing social distancing. In towns RSPs have put up banners for messaging and are using loudspeakers to convey these strategies. RSPs are working closely with community activists in taking safety messages to communities. These activists are providing hygiene kits, where funds are available.

\section{Epidemiology in Pakistan}

Data related by WHO exposed altogether 76,769 cases of COVID-19 were found on 21st, February 2020 and it was confirmed in February 2020 that coronavirus pandemic was reached in Pakistan. The first two cases of the coronavirus were confirmed on February 26,2020 in Pakistan. The Prime Minister's Advisor Zafar Mirza tweet stated that: "I can confirm first two cases of coronavirus in Pakistan. Both cases are being taken care of according to clinical standard protocols \& both of them are stable. The first patient was found at the University of Karachi, Karachi in Sindh province was a student, the second patient was found at federal territory of the country. Both of these patients had just come back from Iran. After confirmed 2 cases, within a week three more cases confirmed in Pakistan's capital, Islamabad and also in Rawalpindi, Punjab (within 15 days), positive COVID-19 tests were reached at 20, 14 cases were from Sindh Province, 1 in a in Baluchistan, and 5 in Gilgit Baltistan. All cases had a history of a recent visit to Syria, London, or Iran. A total of 471 suspected samples had been tested up to 12th March and out of these $20(4.25 \%)$ of which were found to be positive.

After that on 30 marches, confirmed number of cases was reached 1690 , along to 53 recoveries patients and including 18 deaths in the country. Currently, Punjab is the region with the highest 618 number of cases. Weekly and daily based report suggested that number of deaths, and cases remain unsustain or unpredictable. The overall pandemic situation in Pakistan between March to September 2020 is graphically presented in Figure 1.

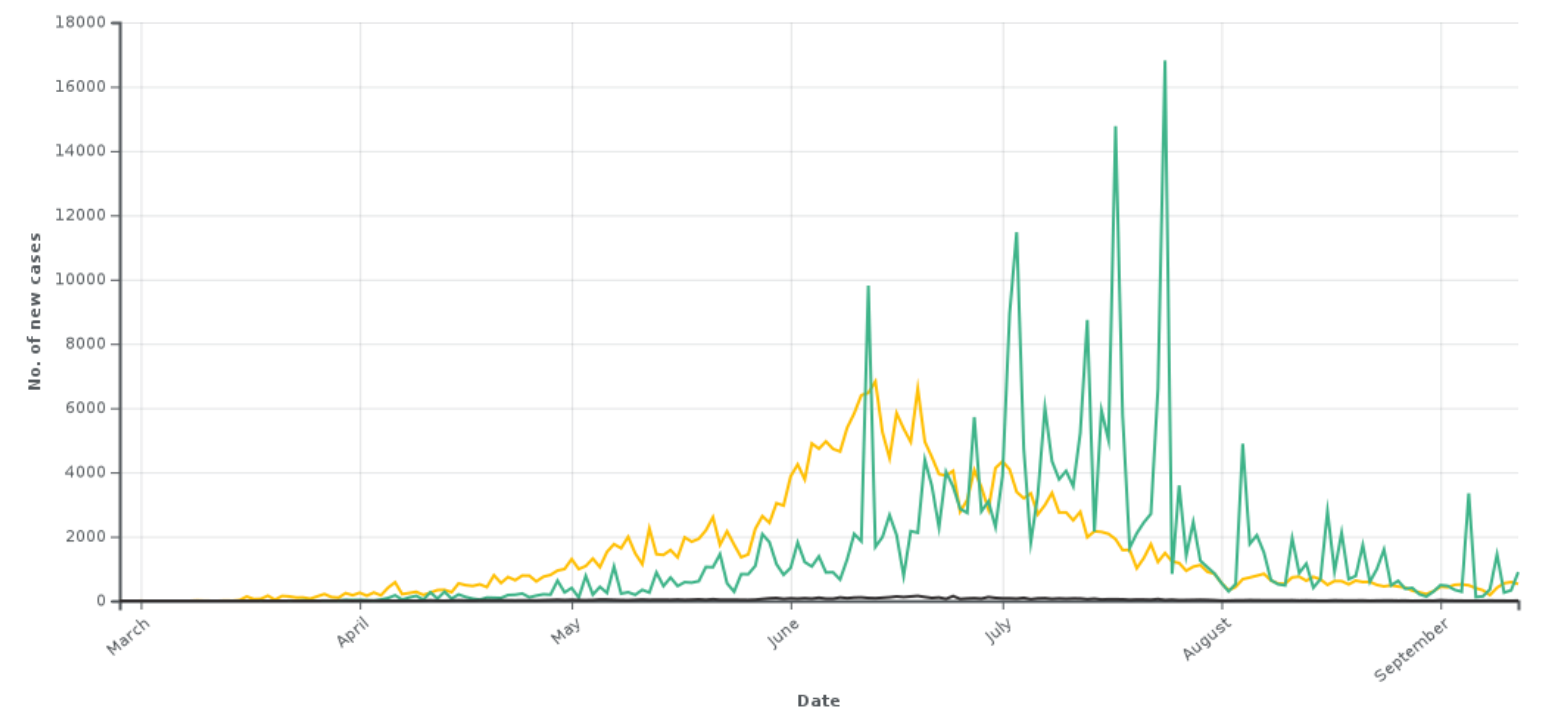

Cumulative Confirmed Cases Cumulative Recoveries Cumulative Deaths

Figure 1. Pandemic situation in Pakistan.

According to the epidemiology of Pakistan, Figure 1 shows current situation of pandemic in Pakistan by linear scale with months. In March, the pandemic began
Source: https://covid.gov.pk/

and until April cases were increased and in June to July pandemic situation was terrible, while during August to September only few pandemic cases were recoded. On 
the other hand, recoveries were also high from July to COVID -19. August. In Pakistan death rate was very low due to

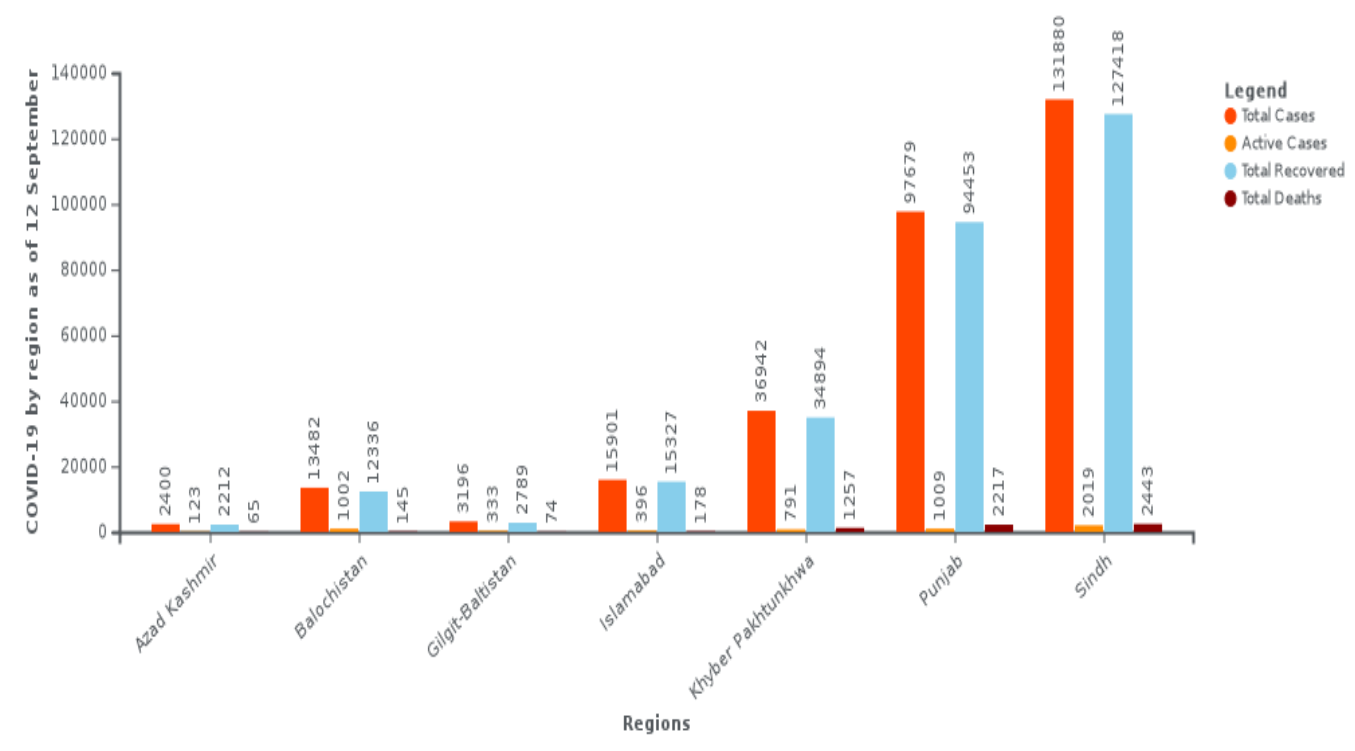

Figure 2. Region wise pandemic situation in Pakistan March to September 2020. Source: https://covid.gov.pk/

In the above figure the Pakistan pandemic situation is presented by region from March to September 2020. The lowest number of confirmed cases in Pakistan were recorded in Azad Kashmir, and then in Gilgit-Baltistan. On the other hand, the highest number of cases were recorded in Sindh and then in Punjab. Therefore, the highest number of active cases were in Singh, and total number of deaths were highest in Singh and then in Punjab.

\section{Symptoms}

The review of different outlet of literature like world Health Organization (WHO), National Command Operation Center (NCOC), and Ministry of Health Services of Pakistan etc. exposed that the infection symptoms of COVID-19 appear after 5.2 days approximately of gestation period (https://www.nih.org.pk). The period dependent on immune system and age of patient. It was petite in patients $>70$ years-old rather than under 70 . The period of initial symptoms of COVID-19 toward death remain 6 - 41 days, while a median of 14 days (https://www.nih.org.pk). The common symptoms of COVID-19 were cough, fatigue and fever, although some other symptoms as headache, sputum production, lymphopenia, diarrhoea, and haemoptysis (Wang, Jianming, et al., 2020; Ren et al., 2020; Huang et al., 2020). The clinical symptoms discovered through CT scan of chest like pneumonia. Nevertheless, there were abnormal features as acute respiratory distress syndrome, RNA anemia, acute cardiac injury that led to patient death. However, there are similarities in the symptoms among COVID-19 and previous beta coronavirus as dyspnea, cough, fever, and on chest CT scans found bilateral ground-glass opacities (Wang, Cao, et al., 2020). Unfortunately, in some cases treatment found no clinical effect exposed with interferon inhalation, instead get worse condition by continuing pulmonary opacities (Lei et al., 2020). It is important to note that COVID-19 presented some clinical features include lower airway as upper respiratory zone signs such as sore throat rhinorrhea, and sneezing. Therefore, results of some cases confirmation an infiltrate in the lung upper lobe that is connected by cumulative dyspnea by hypoxemia (Li et al., 2020).

The clinical features of COVID-19 are pneumonia, ARD, and asymptomatic carrier. Firstly, without any COVID-19 symptoms the asymptomatic cases were diagnosed as positive viral nucleic acid test results, such as gastrointestinal, respiratory problems and fever (Bai et al. 2020; CDC weekly, 2020). Secondly, ARD patients were laboratory-confirmed COVID-19 cases with respiratory symptoms. Thirdly, COVID-19 pneumonia cases were defined with had both

(Pneumonia on chest radiograph and respiratory symptoms). 


\section{Transmission}

The transmission of COVID-19 infected peoples was unprotected by wet animal of in Wuhan City, because their animals were sold routinely. COVID-19 showed 88 percent identification of two extreme bat-derived acute respiratory syndrome (SARS)-like corona viruses (Lu, Stratton, et al., 2020; Wan et al., 2020), suggesting that bats are the most likely link between COVID-19 and humans. Some studies reported that person-to-person transmission is a possible way toward the infection COVID-19. However, no clear evidence of coronavirus was from birds or mammals (Bassetti et al., 2020; Ji et al., 2020).

The first step of viral infection followed with cell membrane of a receptor by host cells. It's hypothesized that the virus 'primary target is the lung epithelial cells. Accordingly, transmissions of SARS-CoV in human-tohuman occur through angiotensin-converting enzyme 2 (ACE2) receptor (Wan et al., 2020; Jaimes et al., 2020). However, latest research supposed the pangolins are possible transitional hosts toward coronavirus, may not the only.

\section{Therapeutics/treatment options}

Person to person transmission of COVID-19 infection contributed to patient's isolation despite a range of treatments. Currently no effective antiviral drugs of COVID- 19 vaccine are available. So, only available option is to use broad-spectrum antiviral drugs such as nucleoside analogs, (Chen et al., 2020). The therapy so far attempted has shown that current antiviral medications have been given to 75 patients. The course of treatment included oral administration of $75 \mathrm{mg}$ oseltamivir, $500 \mathrm{mg}$ lopinavir, $500 \mathrm{mg}$ ritonavir twice a day and $0.25 \mathrm{~g}$ ganciclovir intravenous administration for 3-14 days (Wang, Jianming, et al., 2020). Therefore, the diagnosis of COVID-19 infection may be considered with these therapeutic agents (Wang et al. 2020). However, further work is urgently required to discover treatment of COVID-19 infections. Although, currently numerous scientist groups are working hard to identified COVID- 19 infection therapeutics.

\section{DISCUSSIONS}

In spite of this there is only $75 \%$ similarity in SARS-CoV to genetic sequence (Chan et al., 2020). In 2019n-CoV, many features of SARS-CoV shared like clinical, epidemiological, ACE2, and so on (Guan et al., 2020). No particular therapy proven efficacy for infection with human CoVs has been recommended yet. Retrospective studies found that most CoV deaths were due to serious pneumonia in patients with the infection Changes in immune index also observed in patients with CoV, like monocities, elevated cytokine, and lymphopenia (Li et al., 2020).

In addition to other side effects of corticosteroids treatment can decrease inflammation risk in lung, along with it can suspension the clearance of CoVs (Corneli et al., 2007; Ni et al., 2019; Russell et al., 2020). Hence, corticosteroid issues practice in $\mathrm{CoV}$ patients that has been a subject of debate for years. The clinical evidence available in the treatment of MERS-CoV and SARS-CoV appear for net bene-fit resulting from corticosteroids. Recently, Wuhan's 2019-nCoV the largest case series research found that there was no successful outcome with the use of varied methyl red niso lone dose (Russell et al., 2020). The 2019-nCoV epidemic poses a grave threat for China. Currently, quarantine or detection of infection, supportive diagnosis and therapies for suspected patients are the most important steps for 2019-nCoV. After the SARS-CoV outbreak 17 years ago, major strides have been made in preventing and managing the emerging infectious diseases. Additionally, a series of effective therapies were introduced for patients with 2019-nCoV based on the popular SARS$\mathrm{CoV}$ therapy. Hence, we are optimistic these will effectively curb the 2019-nCoV outbreak. The height of the outbreak will soon be reached, and the final triumph is not far away.

Several antiviral drugs are recently suggested for treating COVID-19, its means to alleviate symptoms that can include cough medicine, pain relievers (paracetamol), or other medications, rest and fluid intake. When doctor feels patient should be handled at home, he or she can give specific orders, like isolating yourself from family and pets as much as possible when you're sick. COVID 19 seriously infects human lives but has some positive effect on people becoming conscious of good personal hygiene, regular hand washing and balanced diet in order to improve health and increase immunity. The dietary behaviors of people are changing enormously, and people are getting more motivated towards benefits of hand washing, healthy dietary habits and taking enough water and appropriate sleep to increase the immunity. There are some guided and indigenous self-protection methods to be carry out 
against COVID 19 e.g., take steam and hot water frequently, cover nose and mouth during cough with mask, tissue, wear mask when go out of home, hand washed regularly by water, soup and alcohol base hand rub, clean surface regularly, used tissue should be discard it immediately into a close bin. Avoid sharing bedding, glasses, dishes, or other household items if you are sick clean and disinfect the surface you often reach every day. When you are sick, stay home from work, school, or public places, unless you are going to get medical treatment. If you're sick stop using public transport. When shopping during the corona virus outbreak, the rules will follow; make sure the shopping cart is sterile or ask a store employee to sterilize. Make sure you stay away from other shoppers when paying at the counter, leave enough space in the line, don't go in big groups and don't take kids, don't panic, after shopping, leave quickly and don't walk around, avoid unwanted interaction with animals, feed well-cooked before consumption.

Rural communities' people remain close to wildlife, pets, livestock and animals. The interactions between animals and people may happen in farming, animal exhibitions, and visiting pets, or while hiking, hunting as well as through other outdoor activities (https://www.cdc.gov/ruralhealth/zoonotic_diseases.ht $\mathrm{ml}$ ). Rural healthcare infrastructure is limited. Rural inhabitants looking for care from hospital, long distances, clinical specialists and health facilities. COVID 19 severely infecting human lives but has some positive impact that people are getting awareness of good personal hygiene, frequent hand washing and healthy diet to promote health and boost up immunity. The dietary patterns of people are changing enormously, and people are getting more motivated towards benefits of hand washing, healthy dietary habits and taking enough water and appropriate sleep to increase the immunity.

\section{Efforts Made in in Pakistan for Alleviating the Spreading of Corona}

Efforts to prevent the spread of the virus include travel restrictions, quarantines, curfews, occupational danger measures, all public marriage gatherings, funerals, celebrations, conferences, and postponement and termination of religious congress. Many of Iran's Zaireen have been in quarantine at Taftan Boarder as well as other country towns. Lockdown was declared March 24,2020 until April 4, 2020. Curfew steps should be taken when conditions will be worst in the months to come. Numerous border limits or incoming restrictions on travellers, screening at airports and railway stations and outgoing travel bans. Some solution of COVID 19 at individual and households' level is clean surfaces using soap and water, then use disinfectants, often hand wash with soap, if someone is sick in house then keep his separate room (if possible). Cleaning around the home and high touch surface in house to clean and clean homes regularly. Make social and physical distancing. Teach to cover their mouth during coughing or sneezing and to throw tissue in garbage after use and wash hands. Encourage to eat healthy and not to eat junk food. Eat healthy food and drink lukewarm water.

\section{CONCLUSION AND RECOMMENDATIONS}

In rural areas Pakistan, tailored communication strategies like village group discussions about vaccination myths, community awareness campaign about threat, prevention and protection of COVID 19 should be launched thru community seminars, workshops, demonstration activities by community leaders and community-based organizations. Special programs/activities should be executed at schools and community levels by the public health care and wellness agencies. Moreover, display of banners, distribution of pamphlets, displaying charts and wall chalking should be started at village central places, market and streets to mitigate the spread of virus.

\section{REFERENCES}

Bassetti, M., A. Vena and D. R. Giacobbe. 2020. The novel Chinese coronavirus (2019-nCoV) infections: Challenges for fighting the storm. European journal of clinical investigation, 50: e13209-e09.

Bogoch, I. I., A. Watts, A. Thomas-Bachli, C. Huber, M. U. G. Kraemer and K. Khan. 2020. Pneumonia of unknown aetiology in Wuhan, China: potential for international spread via commercial air travel. Journal of travel medicine, 27: taaa008.

Chan, J. F.-W., K.-H. Kok, Z. Zhu, H. Chu, K. K.-W. To, S. Yuan and K.-Y. Yuen. 2020. Genomic characterization of the 2019 novel humanpathogenic coronavirus isolated from a patient with atypical pneumonia after visiting Wuhan. Emerging microbes \& infections, 9: 221-36.

Chen, N., M. Zhou, X. Dong, J. Qu, F. Gong, Y. Han, Y. Qiu, J. Wang, Y. Liu, Y. Wei, J. a. Xia, T. Yu, X. Zhang and 
L. Zhang. 2020. Epidemiological and clinical characteristics of 99 cases of 2019 novel coronavirus pneumonia in Wuhan, China: a descriptive study. Lancet (London, England), 395: 507-13.

Corneli, H. M., J. J. Zorc, P. Mahajan, K. N. Shaw, R. Holubkov, S. D. Reeves, R. M. Ruddy, B. Malik, K. A. Nelson, J. S. Bregstein, K. M. Brown, M. N. Denenberg, K. A. Lillis, L. B. Cimpello, J. W. Tsung, D. A. Borgialli, M. N. Baskin, G. Teshome, M. A. Goldstein, D. Monroe, J. M. Dean and N. Kuppermann. 2007. A Multicenter, Randomized, Controlled Trial of Dexamethasone for Bronchiolitis. New England Journal of Medicine, 357: 331-39.

Gorbalenya, A. E., S. C. Baker, R. S. Baric, R. J. de Groot, C. Drosten, A. A. Gulyaeva, B. L. Haagmans, C. Lauber, A. M. Leontovich and B. W. Neuman. 2020. Severe acute respiratory syndromerelated coronavirus: The species and its viruses-a statement of the Coronavirus Study Group. BioRxiv.

Guan, W.-j., Z.-y. Ni, Y. Hu, W.-h. Liang, C.-q. Ou, J.-x. He, L. Liu, H. Shan, C.-1. Lei and D. S. Hui. 2020. Clinical characteristics of 2019 novel coronavirus infection in China. MedRxiv.

Huang, C., Y. Wang, X. Li, L. Ren, J. Zhao, Y. Hu, L. Zhang, G. Fan, J. Xu, X. Gu, Z. Cheng, T. Yu, J. Xia, Y. Wei, W. Wu, X. Xie, W. Yin, H. Li, M. Liu, Y. Xiao, H. Gao, L. Guo, J. Xie, G. Wang, R. Jiang, Z. Gao, Q. Jin, J. Wang and B. Cao. 2020. Clinical features of patients infected with 2019 novel coronavirus in Wuhan, China. Lancet (London, England), 395: 497-506.

Jaimes, J. A., J. K. Millet, A. E. Stout, N. M. André and G. R. Whittaker. 2020. A Tale of Two Viruses: The Distinct Spike Glycoproteins of Feline Coronaviruses. Viruses, 12: 83.

Ji, W., W. Wang, X. Zhao, J. Zai and X. Li. 2020. Crossspecies transmission of the newly identified coronavirus 2019-nCoV. Journal of medical virology, 92: 433-40.

Lei, J., J. Li, X. Li and X. Qi. 2020. CT Imaging of the 2019 Novel Coronavirus (2019-nCoV) Pneumonia. Radiology, 295: 18-18.

Li, G., Y. Fan, Y. Lai, T. Han, Z. Li, P. Zhou, P. Pan, W. Wang, D. Hu, X. Liu, Q. Zhang and J. Wu. 2020.
Coronavirus infections and immune responses. Journal of medical virology, 92: 424-32.

Lu, H., C. W. Stratton and Y.-W. Tang. 2020. Outbreak of pneumonia of unknown etiology in Wuhan, China: The mystery and the miracle. Journal of medical virology, 92: 401-02.

Lu, R., X. Zhao, J. Li, P. Niu, B. Yang, H. Wu, W. Wang, H. Song, B. Huang, N. Zhu, Y. Bi, X. Ma, F. Zhan, L. Wang, T. Hu, H. Zhou, Z. Hu, W. Zhou, L. Zhao, J. Chen, Y. Meng, J. Wang, Y. Lin, J. Yuan, Z. Xie, J. Ma, W. J. Liu, D. Wang, W. Xu, E. C. Holmes, G. F. Gao, G. Wu, W. Chen, W. Shi and W. Tan. 2020. Genomic characterisation and epidemiology of 2019 novel coronavirus: implications for virus origins and receptor binding. Lancet (London, England), 395: 565-74.

Ni, Y.-N., G. Chen, J. Sun, B.-M. Liang and Z.-A. Liang. 2019. The effect of corticosteroids on mortality of patients with influenza pneumonia: a systematic review and meta-analysis. Critical care (London, England), 23: 99-99.

Ren, L.-L., Y.-M. Wang, Z.-Q. Wu, Z.-C. Xiang, L. Guo, T. Xu, Y.-Z. Jiang, Y. Xiong, Y.-J. Li, X.-W. Li, H. Li, G.-H. Fan, X.-Y. Gu, Y. Xiao, H. Gao, J.-Y. Xu, F. Yang, X.M. Wang, C. Wu, L. Chen, Y.-W. Liu, B. Liu, J. Yang, X.-R. Wang, J. Dong, L. Li, C.-L. Huang, J.-P. Zhao, Y. Hu, Z.-S. Cheng, L.-L. Liu, Z.-H. Qian, C. Qin, Q. Jin, B. Cao and J.-W. Wang. 2020. Identification of a novel coronavirus causing severe pneumonia in human: a descriptive study. Chinese medical journal, 133: 1015-24.

Russell, C. D., J. E. Millar and J. K. Baillie. 2020. Clinical evidence does not support corticosteroid treatment for 2019-nCoV lung injury. Lancet (London, England), 395: 473-75.

Wan, Y., J. Shang, R. Graham, R. S. Baric and F. Li. 2020. Receptor Recognition by the Novel Coronavirus from Wuhan: an Analysis Based on Decade-Long Structural Studies of SARS Coronavirus. Journal of virology, 94: e00127-20.

Wang, M., R. Cao, L. Zhang, X. Yang, J. Liu, M. Xu, Z. Shi, Z. Hu, W. Zhong and G. Xiao. 2020. Remdesivir and chloroquine effectively inhibit the recently emerged novel coronavirus (2019-nCoV) in vitro. Cell research, 30: 269-71.

Wang, W., T. Jianming and W. Fangqiang. 2020. Updated understanding of the outbreak of 2019 novel 
Publisher's note: EScience Press remains neutral with regard to jurisdictional claims in published maps and institutional affiliations.

Open Access This article is licensed under a Creative Commons Attribution 4.0 International License, which permits use, sharing, adaptation, distribution and reproduction in any medium or format, as long as you give appropriate credit to the original author(s) and the source, provide a link to the Creative Commons license and indicate if changes were made. The images or other third-party material in this article are included in the article's Creative Commons license, unless indicated otherwise in a credit line to the material. If material is not included in the article's Creative Commons license and your intended use is not permitted by statutory regulation or exceeds the permitted use, you will need to obtain permission directly from the copyright holder. To view a copy of this license, visit http://creativecommons.org/licenses/by/4.0/. 